\title{
Analisis Kebutuhan Pembangunan Tempat Pemakaman Umum di Perkotaan Tuban
}

\author{
Analysis of the Needs for Public Cemetery Construction in Tuban \\ Urban Area
}

\section{Arwi Yudhi Koswara ${ }^{1}$, Eko Budi Santoso ${ }^{1}$, Abdul Afif ${ }^{2}$, Teti Hariyati², Sutikno, Ema Umilia ${ }^{1}$, Prianti $^{1}$, Rahel Putri Pamungkas ${ }^{1}$, Chichik IImi Annisa ${ }^{1}$}

\begin{abstract}
Abstrak: Ketersediaan lahan di sejumlah Tempat Pemakaman Umum di Perkotaan Tuban saat ini mengalami tekanan terhadap kapasitas dan daya tampungnya yang semakin sempit dan terbatas akibat pertambahan jumlah penduduk serta fasilitas yang kurang memadai. Pada penelitian ini dilakukan perhitungan untuk mengetahui luasan dan daya tampung lahan makam di Perkotaan Tuban. Kegiatan yang dilakukan pada tahap pengumpulan data meliputi survey primer dan sekunder. Kegiatan survei primer yang dilakukan meliputi survei lapangan dan penjaringan aspirasi masyarakat yang dilakukan melalui wawancara mendalam (in-depth interview) maupun Focus Group Discussion (FGD). Sedangkan survei sekunder dilakukan untuk pemenuhan data meliputi data dasar hukum dan kebijakan, data data kondisi sosial kependudukan. Metode analisis yang digunakan yaitu analisis kebutuhan makam dengan menganalisis proyeksi angka kematian, menghitung kebutuhan luas lahan pemakaman pertahun, menghitung luas lahan tersisa, menghitung daya tampung lahan tersisa makam dan menghitung daya tampung tersisa makam dengan sistem sekali tumpang susun. Dari hasil analisis diperoleh kemampuan daya tampung tersisa lahan pemakaman Kecamatan Tuban akan terisi penuh pada tahun 2021 dan akan membutuhkan luasan lahan tambahan seluas $617.945 \mathrm{~m} 2$ (61 Ha) pada tahun 2030. Kecamatan Semanding dan Merakurak diproyeksi akan penuh pada tahun 2025 dengan kebutuhan luas lahan sebesar $81.589 \mathrm{~m} 2$ (8,1 Ha)dan $113.875 \mathrm{~m} 2$ (11 Ha) pada tahun 2030 Kecamatan palang akan penuh pada tahun 2026 dan Kecamatan Jenu akan penuh pada tahun 2028.
\end{abstract}

Kata kunci: Analisis Kebutuhan Makam, Daya Tampung Pemakaman, Tempat Pemakaman Umum.

\begin{abstract}
Tuban currently under pressure towards the land capacity which is getting limited due to the population growth and inadequate facilities. This study, using the calculation to get the estimated area and the land capacity of the public cemetery in Tuban. The data compilation steps consists of primary survey and secondary survey. The primary survey activities carried out included field surveys and community aspirations which were carried out through in-depth interviews and Focus Group Discussions (FGD). Meanwhile, the secondary survey was conducted to find data, namely basic data on laws and policies, and data on social demographic conditions. The analytical method used is the analysis of grave needs by analyzing the projection of the mortality rate, calculating the need for cemetery land area per year, calculating the remaining land area for the cemetery, calculating the remaining land capacity of the cemetery, and calculating the remaining capacity of the cemetery with a one-time overlapping system. From the results of the analysis, it is obtained that the remaining capacity of the burial ground in Tuban District will be filled in 2021 and
\end{abstract}

\footnotetext{
${ }^{1}$ Institut Teknologi Sepuluh Nopember Surabaya

${ }^{2}$ Pemerintah Kabupaten Tuban
}

Korespondensi: arwiyudhi@gmail.com 
will require an additional land area of 617,945 m2 (61 Ha) in 2030. Semanding and Merakurak Districts are projected to be full in 2025 with a land area requirement of 81,589 $\mathrm{m} 2(8.1 \mathrm{Ha})$ and 113,875 $\mathrm{m} 2$ (11 Ha) in 2030 Palang District will be full in 2026 and Jenu District will be full in 2028.

Keywords: Analysis of cemetery needs, cemetery capacity, public cemetery.

\section{PENDAHULUAN}

Tempat Pemakaman Umum (TPU) merupakan sarana yang dibutuhkan penduduk di perkotaan. Tempat Pemakaman Umum juga dapat difungsikan sebagai salah satu ruang terbuka hijau di perkotaan. Sayangnya penyediaan sarana TPU kurang mendapatkan perhatian yang cukup dari pemerintah daerah. TPU yang tersedia umumnya merupakan TPU milik Pemerintah Desa. Akibatnya seringkali dijumpai kondisi dimana jenazah yang akan dimakamkan di areal tanah makam desa ditolak oleh warga setempat karena bukan penduduk asli desa, yang diprioritaskan hanya bagi masyarakat setempat yang masih satu desa. Oleh sebab itu diperlukan penyediaan areal pemakaman untuk jenazah tanpa membedakan asal maupun golongan penduduk. Fenomena yang terjadi saat ini terkait dengan pemakaman jenazah pasien penderita Covid-19 sering terjadi penolakan dari masyarakat setempat. Sementara alternatif areal Tempat Pemakaman Umum (TPU) terbatas bahkan tidak tersedia secara memadai.

Lokasi areal TPU yang ada saat ini, kenyataanya banyak terletak di tengah-tengah kota atau berada dalam daerah pemukiman yang banyak penduduknya, sehingga tidak sesuai lagi dengan perencanaan pembangunan daerah atau rencana tata ruang kota. Demikian pula untuk melakukan perluasan areal makam juga terkendala dengan kepadatan penduduk dan bangunan di sekitarnya. Lahan permakaman yang ada saat ini sudah dimanfaatkan lebih dari dua hingga tiga generasi sehingga pemanfaatan liang makan dilakukan secara bertumpuk atau susun (tumpang-susun). Kondisi ini umumnya diberlakukan untuk jenazah yang masih ada hubungan saudara atau kekerabatan untuk mengoptimalkan lahan yang masih tersisa.

Ketersediaan lahan di sejumlah Tempat Pemakaman Umum di Perkotaan Tuban saat ini mengalami tekanan terhadap kapasitas dan daya tampungnya yang semakin sempit dan terbatas akibat pertambahan jumlah penduduk serta fasilitas yang kurang memadai. Sudah saatnya pemerintah daerah memberikan perhatian dan turut serta berperan aktif dalam pengelolaan areal TPU di Perkotaan Tuban dengan tujuan untuk memberikan pelayanan kepada masyarakat dalam urusan permakaman agar penataan makam dapat dilakukan lebih terencana, efisien dan efektif, serta mewujudkan lingkungan hunian yang terintegrasi dengan ruang terbuka hijau.

Untuk melaksanakan tugas dan fungsi pemerintah di bidang pelayanan makam maka dibutuhkan ketersediaan lahan yang cukup guna peruntukan pemakaman di Kota Tuban sehingga perlu dilakukan pengelolaan yang komprehensif dan terpadu dengan penataan ruang yang ada dioptimalkan fungsinya selain untuk pemakaman jenazah dan juga bisa difungsikan sebagai bagian ruang terbuka hijau pada kawasan perkotaan untuk menambah unsur keindahan, mampu berperan sebagai resapan air, dan juga berfungsi untuk pelestarian/pelindung lingkungan.

Berdasarkan permasalahan di atas dipandang perlu dilakukan kajian tentang analisa kebutuhan tempat pemakaman umum. Hal ini dilakukan sebagai upaya agar pengelolaan dan pemanfaatan lahan yang diperuntukkan sebagai TPU dapat berlangsung dengan memperhatikan kelestarian lingkungan, optimasi pemanfaatan lahan, berkelanjutan serta memperhatikan kepentingan aspek religius, sosial budaya dan juga dalam hal kesesuaian penggunaan serta pemanfaatan lahan. 


\section{METODE}

\section{Ruang Lingkup Studi}

Wilayah Kajian studi ini adalah di Kecamatan Tuban dan Kecamatan Sekitarnya (Kecamatan Semanding, Kecamatan Merakurak, dan Kecamatan Jenu) dengan output penelitian merumuskan rekomendasi tindak lanjut dan kebijakan rencana pembangunan TPU Perkotaan Tuban.

\section{Metode Pengumpulan Data}

Kegiatan yang dilakukan pada tahap pengumpulan data meliputi survey primer dan sekunder. Kegiatan survei primer yang dilakukan meliputi survei lapangan dan penjaringan aspirasi masyarakat yang dilakukan melalui wawancara mendalam (in-depth interview) maupun Focus Group Discussion (FGD). Sedangkan survei sekunder dilakukan untuk pemenuhan data meliputi data dasar hukum dan kebijakan, data penggunaan lahan dan data kondisi sosial kependudukan.

\section{Metode Analisis}

\section{Analisis Kebutuhan Makam}

Analisis ketersediaan lahan TPU dihitung dengan beberapa tahapan (Ghea Amalia,2016) Yaitu:

a. Estimasi rata-rata angka kematian per tahun

$$
\mathbf{R A K}=\sum\left(\frac{A K 1+A K 2+A K 3+A K 4+A K 5)}{N}\right.
$$

Keterangan:

$\begin{array}{ll}\text { RAK } & : \text { Rata-Rata Angka Kematian (jenazah/tahun) } \\ \text { AK } & : \text { Angka Kematian Tahun Ke-1, 2, 3, Dan Seterusnya (jenazah) } \\ \text { N } & \text { : Rentang Tahun Perhitungan (tahun) }\end{array}$

b. Estimasi kebutuhan luas lahan makam per tahun.

\section{KLP = RAKXLM}

Keterangan:

KLP : Kebutuhan Luas Lahan Pemakaman $\left(\mathrm{m}^{2} /\right.$ tahun)

RAK : Rata-Rata Angka Kematian (jenazah/tahun)

LM : Luas Yang Dibituhkan Tiap Makam $\left(3,84 \mathrm{~m}^{2}\right)$

c. Estimasi luas lahan tersisa makam

LTs $=$ Ltot-LTp

Keterangan :

LTs : Luas Lahan Tersisa $\left(\mathrm{m}^{2}\right)$

Ltotal : : Luas Lahan Pemakaman Total $\left(\mathrm{m}^{2}\right)$

LTp : Luas Lahan Terpakai $\left(\mathrm{m}^{2}\right)$

d. Untuk menghitung kemampuan daya tampung tersisa lahan pemakaman dilakukan dengan mengasumsikan setiap jenazah membutuhkan luas lahan sesuai dengan kondisi di lapangan pada umumnya dan tidak menggunakan sistem tumpang susun. 


$$
\text { Dta }=\frac{L T S}{L M}
$$

Keterangan:

$\begin{array}{ll}\text { Dta } & \text { : Daya Tampung Tanpa Tumpang Susun (jenazah) } \\ \text { LTs } & \text { : Luas Lahan Tersisa }\left(\mathrm{m}^{2}\right) \\ \text { LM } & \text { : Luas Yang Dibutuhkan Tiap Makam }\left(3,84 \mathrm{~m}^{2}\right)\end{array}$

e. Untuk menghitung kemampuan daya tampung tersisa lahan pemakaman dengan memakai sekali sistem makam tumpang dilakukan dengan menjumlahkan daya tampung dengan luas total yang sudah dibagi dengan luas maksimum tiap makam.

$$
\mathrm{DTb}=\quad \mathrm{DT} a+\frac{\text { Ltotal }}{L M}
$$

Keterangan :

DTb :Daya Tampung Dengan Sekali Tumpang Susun (Jenazah)

L $\quad$ :Luas Total Lahan Makam $\left(\mathrm{m}^{2}\right)$

LM :Luas Maksimum Tiap Makam (3,84 $\left.\mathrm{m}^{2}\right)$

Setelah dilakukan perhitungan DTa dan DTb, langkah yang dilakukan yaitu membandingkan rata-rata angka kematian per tahun untuk mengetahui prediksi habis masa pakai lahan pemakaman di Perkotaan Tuban.

$$
\begin{array}{ll}
\mathrm{PMPa}= & \frac{D T a}{R A K} \\
\mathrm{PMPb}= & \frac{D T b}{R A K}
\end{array}
$$

Keterangan:

PMPa : : Prediksi Masa Pakai Tanpa Tumpang Susun (tahun)

DTa $\quad$ : Daya Tampung Tanpa Tumpang Susun (jenazah)

$\mathrm{PMPb} \quad$ : Prediksi Masa Pakai Dengan Sekali Tumpang Susun (tahun)

DTb : : Daya Tampung Dengan Sekali Tumpang Susun (Jenazah)

RAK : Rata-Rata Angka Kematian (Jenazah/Tahun)

\section{HASIL DAN PEMBAHASAN}

\section{Analisis Kebutuhan Makam}

\section{Perhitungan Rata-Rata Angka Kematian Per Tahun}

Rata rata angka kematian di Perkotaan Tuban selama 3 tahun adalah 10.385 jiwa pertahun. Rata-rata angka kematian tertinggi di Kecamatan Tuban dengan jumlah kematian sebesar 2.814 jiwa pertahun dan kecamatan jenu merupakan kecamatan dengan rata-rata angka kematian terendah dengan kematian 1.189 jiwa per tahun. kematian 1.189 jiwa pertahun.

Tabel 1. Rata-Rata Angka Kematian Per Tahun

\begin{tabular}{llrrrc}
\hline No. & Kecamatan & \multicolumn{3}{c}{ Jumlah Kematian } & Rata rata \\
& & 2017 & 2018 & 2019 & kematian \\
\hline 1 & Jenu & 997 & 1.198 & 1.371 & 1.189 \\
2 & Merakurak & 1.399 & 1.625 & 1.845 & 1.623 \\
3 & Semanding & 2.844 & 2.373 & 2.877 & 2.698 \\
4 & Tuban & 2.195 & 2.834 & 3.414 & 2.814
\end{tabular}




\begin{tabular}{clrrrc}
\hline No. & Kecamatan & \multicolumn{3}{c}{ Jumlah Kematian } & Rata rata \\
& & 2017 & 2018 & 2019 & kematian \\
\cline { 3 - 5 } 5 & Palang & 1.606 & 2.031 & 2.545 & 2.061 \\
& Total Perkotaan Tuban & 9.041 & 10.061 & 12.052 & 10.385 \\
\hline
\end{tabular}

Sumber: Hasil analisis, 2020

\section{Proyeksi Angka Kematian}

Proyeksi angka kematian digunakan untuk memprediksi kebutuhan lahan pemakaman yang akan digunakan dalam sepuluh tahun kedepan. Dari hasil perhitungan proyeksi angka kematian selama 10 tahun kedepan jumlah angka kematian di tahun 2030 di Perkotaan Tuban sejumlah 91.131 Jiwa. Angka kematian tertinggi di di Kecamatan Tuban dengan 39011 Jiwa dan disusul Kecamatan Palang dengan 32.020 Jiwa. Berikut adalah hasil proyeksi angka kematian di Perkotaan Tuban.

Tabel 2. Proyeksi Angka Kematian Perkotaan Tuban Tahun 2020-2030

\begin{tabular}{|c|c|c|c|c|c|c|c|c|c|c|c|c|}
\hline \multirow[t]{2}{*}{ KEC } & \multirow{2}{*}{$\begin{array}{c}\text { Rerata } \\
\text { Laju } \\
\text { Angka } \\
\text { Kemati } \\
\text { an }\end{array}$} & \multicolumn{11}{|c|}{ Proyeksi Angka Kematian } \\
\hline & & 2020 & 2021 & 2022 & 2023 & 2024 & 2025 & 2026 & 2027 & 2028 & 2029 & 2030 \\
\hline Jenu & $17,30 \%$ & 1.608 & 1.886 & 2.213 & 2.596 & $\begin{array}{c}3.04 \\
5\end{array}$ & 3.571 & 4.189 & $\begin{array}{c}4.91 \\
4\end{array}$ & 5.764 & $\begin{array}{c}6.76 \\
1\end{array}$ & 7.931 \\
\hline Merakurak & $14,85 \%$ & 2.119 & 2.434 & 2.795 & 3.210 & $\begin{array}{c}3.68 \\
6\end{array}$ & 4.234 & 4.862 & $\begin{array}{c}5.58 \\
4\end{array}$ & 6.413 & $\begin{array}{c}7.36 \\
5\end{array}$ & 8.458 \\
\hline $\begin{array}{l}\text { Semandin } \\
\mathrm{g}\end{array}$ & $2,34 \%$ & 2.944 & 3.013 & 3.084 & 3.156 & $\begin{array}{c}3.23 \\
0\end{array}$ & 3.305 & 3.382 & $\begin{array}{c}3.46 \\
2\end{array}$ & 3.542 & $\begin{array}{c}3.62 \\
5\end{array}$ & 3.710 \\
\hline Tuban & $24,79 \%$ & 4.260 & 5.316 & 6.634 & 8.279 & $\begin{array}{c}10.3 \\
31\end{array}$ & 12.892 & $\begin{array}{c}16.08 \\
8\end{array}$ & $\begin{array}{c}20.0 \\
75\end{array}$ & 25.052 & $\begin{array}{c}31.2 \\
62\end{array}$ & 39.011 \\
\hline Palang & $25,89 \%$ & 3.204 & 4.033 & 5.077 & 6.391 & $\begin{array}{c}8.04 \\
6\end{array}$ & 10.128 & $\begin{array}{c}12.75 \\
0\end{array}$ & $\begin{array}{c}16.0 \\
51\end{array}$ & 20.205 & $\begin{array}{c}25.4 \\
36\end{array}$ & 32.020 \\
\hline $\begin{array}{l}\text { Total } \\
\text { Perkotaan }\end{array}$ & $17,03 \%$ & $\begin{array}{c}14.13 \\
5\end{array}$ & $\begin{array}{c}16.68 \\
3\end{array}$ & 19.802 & $\begin{array}{c}23.63 \\
1\end{array}$ & $\begin{array}{c}28.3 \\
37\end{array}$ & 34.130 & $\begin{array}{c}41.27 \\
1\end{array}$ & $\begin{array}{c}50.0 \\
86\end{array}$ & 60.977 & $\begin{array}{c}74.4 \\
49\end{array}$ & 91.131 \\
\hline
\end{tabular}

Sumber: Hasil analisis, 2020

\section{Estimasi Kebutuhan Luas Lahan Pemakaman Per Tahun}

Untuk mengetahuan kebutuhan luas makam pertahun dihitung dengan mengalikan angka kematian dengan luas yang dibutuhkan tiap makam dengan standar setiap makam membutuhkan lahan seluas 3,84 $\mathrm{m}^{2}$. Dari hasil perhitungan, Pada tahun 2030 untuk perkotaan Tuban membutuhkan 454.633,6 $\mathrm{m}^{2}$ (45,4 $\left.\mathrm{Ha}\right)$ lahan pemakaman. Dengan kebutuhan lahan makam tertinggi di kecamatan Tuban dengan 179.200,6 $\mathrm{m}^{2}$ (17,9 Ha). Kecamatan semanding membutuhkan 36.453,3 $\mathrm{m}^{2}$ (3,6 Ha) Kecamatan Palang membutuhkan 143.341,5 $\mathrm{m}^{2}$ (14,3 Ha) Kecamatan Merakurak membutuhkan seluas $51.158,9 \mathrm{~m}^{2}(5,11 \mathrm{Ha})$ dan Kecamatan Jenu membutuhkan lahan makam seluas 44.479,3 $\mathrm{m}^{2}$ (4,44 Ha) . Berikut adalah Kebutuhan Luas Lahan Pemakaman di Perkotaan Tuban.

\section{Estimasi Luas Lahan Tersisa}

Dari hasil survei primer, sebagian besar makam di Perkotaan Tuban dalam kondisi padat dengan keterisian $60-90 \%$ dari lahan makam. Untuk menghitung luas lahan tersisa dilakukan pengurangan dari luas lahan pemakaman total (lahan makam eksisting) dengan Luas lahan terpakai sehingga diperoleh luas lahan tersisa. Berikut adalah gambaran makam di Perkotaan Tuban. 
Tabel 1. Kebutuhan Luas Lahan Pemakaman Perkotaan Tuban Tahun 2020-2030

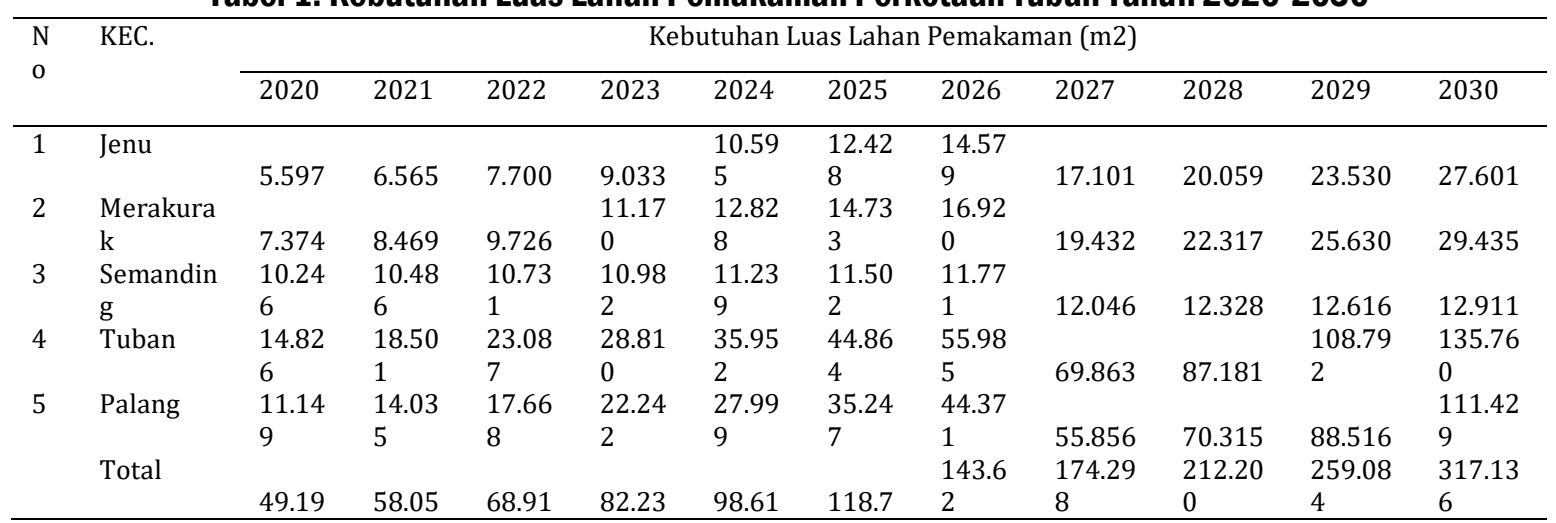

Sumber: Hasil analisis, 2020
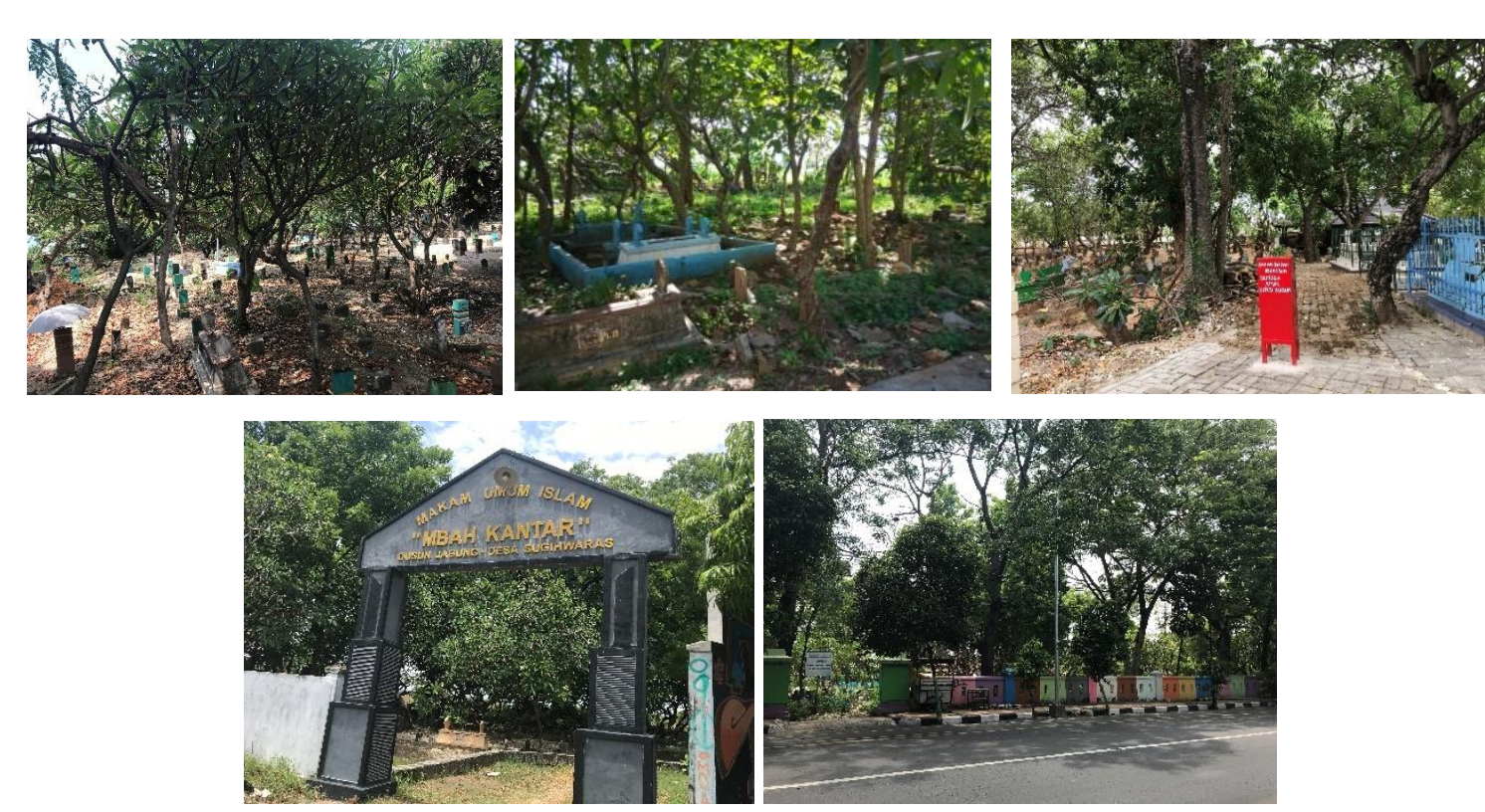

Sumber: Hasil analisis, 2020

\section{Gambar 1. Kondisi keterisian lahan makam di Kec. Tuban, Kec. Semanding, Kec. Merakurak, Kec. Jenu dan Kec. Palang Perkotaan Tuban}

Tabel 2. Luas Total Lahan Terpakai Tiap Tahun dari tahun 2020-2030

\begin{tabular}{|c|c|c|c|c|c|c|c|c|c|c|c|c|}
\hline \multirow[t]{2}{*}{ No. } & \multirow[t]{2}{*}{ Kecamatan } & \multicolumn{11}{|c|}{ Lahan Makam Terpakai Jumlah Tiap Tahun } \\
\hline & & 2020 & 2021 & 2022 & 2023 & 2024 & 2025 & 2026 & 2027 & 2028 & 2029 & 2030 \\
\hline \multirow[t]{2}{*}{1} & \multirow[t]{2}{*}{ Jenu } & \multirow{2}{*}{5.597} & 12.1 & 19.86 & 28.89 & 39.49 & 51.91 & 66.49 & 83.59 & 103.65 & 127.18 & 154.78 \\
\hline & & & 61 & 2 & 4 & 0 & 8 & 7 & 8 & 7 & 7 & 8 \\
\hline \multirow[t]{2}{*}{2} & \multirow[t]{2}{*}{ Merakurak } & \multirow{2}{*}{7.374} & 15.8 & 25.56 & 36.73 & 49.56 & 64.29 & 81.21 & 100.6 & 122.96 & 148.59 & 178.03 \\
\hline & & & 42 & 8 & 8 & 6 & 9 & 9 & 51 & 8 & 8 & 3 \\
\hline \multirow[t]{2}{*}{3} & \multirow[t]{2}{*}{ Semanding } & 10.24 & 20.7 & 31.46 & 42.44 & 53.68 & 65.18 & 76.95 & 89.00 & 101.33 & 113.94 & 126.85 \\
\hline & & 6 & 32 & 3 & 5 & 4 & 6 & 6 & 2 & 0 & 6 & 7 \\
\hline \multirow[t]{2}{*}{4} & \multirow[t]{2}{*}{ Tuban } & 14.82 & 33.3 & 56.41 & 85.22 & 121.1 & 166.0 & 222.0 & 291.8 & 379.06 & 487.85 & 623.61 \\
\hline & & 6 & 27 & 4 & 4 & 75 & 39 & 24 & 86 & 7 & 9 & 8 \\
\hline \multirow[t]{4}{*}{5} & \multirow[t]{2}{*}{ Palang } & 11.14 & 25.1 & 42.85 & 65.09 & 93.09 & 128.3 & 172.7 & 228.5 & 298.88 & 387.39 & 498.82 \\
\hline & & 9 & 84 & 3 & 4 & 4 & 41 & 11 & 68 & 3 & 9 & 9 \\
\hline & \multirow[t]{2}{*}{ Total } & 49.19 & 107. & 176.1 & 258.3 & 357.0 & 475.7 & 619.4 & 793.7 & 1.005 .9 & 1.264 .9 & 1.582 .1 \\
\hline & & 1 & 247 & 59 & 96 & 09 & 82 & 07 & 05 & 05 & 89 & 25 \\
\hline
\end{tabular}

Sumber: Hasil analisis, 2020 
Tabel 3. Luas Lahan Tersisa Makam Tahun 2020

\begin{tabular}{llllll}
\hline No. & Kecamatan & $\begin{array}{c}\text { Luasan Makam } \\
\text { Eksisting (Ha) }\end{array}$ & $\begin{array}{c}\text { Persentase Luas } \\
\text { Lahan Terpakai }\end{array}$ & $\begin{array}{c}\text { Persentase Luas } \\
\text { Lahan Tersisa } \\
\text { Makam }\end{array}$ & $\begin{array}{c}\text { Luas Lahan Tersisa } \\
\text { makam (m2) }\end{array}$ \\
\hline 1 & Jenu & 24,3265 & $50 \%$ & $50 \%$ & $121.632,500$ \\
2 & Merakurak & 16 & $50 \%$ & $50 \%$ & 80.000 \\
3 & Semanding & 22 & $70 \%$ & $30 \%$ & 66.000 \\
4 & Tuban & 39 & $80 \%$ & $20 \%$ & 78.000 \\
5 & Palang & 37,032 & $50 \%$ & $50 \%$ & 185.160 \\
\hline & Total & 138,3585 & $60 \%$ & $40 \%$ & 553.434 \\
\hline
\end{tabular}

Sumber: Hasil analisis, 2020

\section{Estimasi Kemampuan Daya Tampung Tersisa Lahan Pemakaman}

Setelah mengetahui luas lahan tersisa maka dilakukan perhitungan kemampuan daya tampung sisa lahan pemakaman dengan asumsi setiap jenazah membutuhkan luas lahan sesuai dengan kondisi di lapangan pada umumnya dan tidak memakan sistem tumpang susun. Untuk menghitung daya tampung tanpa tumpang susun dihitung dengan membagi antara lahan tersisa dengan luas yang dibutuhkan tiap makam $(3,84 \mathrm{~m} 2)$. Sehingga diperoleh kemampuan daya tampung pemakaman tiap kecamatan di Perkotaan Tuban.

Dari hasil perhitungan luas lahan makam tersisa ditemukan bahwa lahan Pemakaman Kecamatan Tuban akan terisi penuh pada tahun 2021 dan akan membutuhkan luasan lahan tambahan seluas $617.945 \mathrm{~m} 2$ (61 Ha) pada tahun 2030. Kecamatan Semanding dan Merakurak diproyeksi akan penuh pada tahun 2025 dengan kebutuhan luas lahan sebesar $81.589 \mathrm{~m} 2$ dan $113.875 \mathrm{~m} 2$ pada tahun 2030 Kecamatan palang akan penuh pada tahun 2026 dan Kecamatan Jenu akan penuh pada tahun 2028. Hingga pada tahun 2030 Tempat Pemakaman Umum di seluruh kecamatan di Perkotaan Tuban diproyeksikan sudah tidak lagi dapat menampung jenazah baru.

\section{Estimasi Kemampuan Daya Tampung Tersisa Lahan Pemakaman Dengan Sekali Sistem Makam Tumpang}

Dalam tahap analisis penghitungan kemampuan daya tampung tersisa lahan pemakaman dengan sekali sistem makam tumpang, dilakukan dengan menjumlahkan daya tampung dengan sekali tumpang susun dengan total luas yang telah dibagi dengan luas maksimum makam. Dari perhitungan tersebut diperoleh kemampuan daya tampung tersisa lahan pemakaman dengan memakai sekali sistem makam tumpang.

Dari hasil perhitungan kemampuan daya tampung tersisa lahan pemakaman dengan memakai sekali sistem makam tumpang diperoleh hasil bahwa prediksi habis masa pakai lahan pemakaman di Kecamatan Tuban akan penuh pada tahun tahun 2024 dengan kebutuhan lahan sebesar $-25.476,5 \mathrm{~m} 2(2,54 \mathrm{Ha})$ pada tahun 2030 kebutuhan lahan makam mencapai -516.382 m2 (51,6 Ha). Kecamatan Palang dan Merakurak akan penuh pada tahun 2027 dengan kebutuhan luasan lahan sebesar 242.415,42 m2 (24,2 Ha) dan $72.208,655 \mathrm{~m} 2$ (7,2 Ha) pada tahun 2030. Kecamatan semanding akan penuh pada tahun 2028 dengan kebutuhan lahan pada tahun 2030 sebesar 24.297,61 m2 (2,4 Ha). Sedangkan Kecamatan Jenu merupakan satu satunya kecamatan yang masih mampu menampung jenasah baru hingga tahun 2030 dengan sistem makam tumpang. Dengan demikian maka penyediaan lahan untuk tempat pemakaman umum di Kecamatan Tuban perlu diprioritaskan karena akan mengalami defisit penyediaan lahan TPU dalam jangka 
pendek. Upaya yang dilakukan dapat melalui perluasan lahan makam eksisting maupun pencarian lokasi baru yang sesuai kriteria peruntukannya.

\section{KESIMPULAN}

Ketersediaan lahan di sejumlah Tempat Pemakaman Umum di Perkotaan Tuban saat ini mengalami tekanan terhadap kapasitas dan daya tampungnya yang semakin sempit dan terbatas akibat pertambahan jumlah penduduk serta fasilitas yang kurang memadai. Kemampuan Daya Tampung Tersisa Lahan Pemakaman Kecamatan Tuban akan terisi penuh pada tahun 2021, sedangkan Kecamatan Semanding dan Kecamatan Merakurak diproyeksi akan penuh pada tahun 2025, dan Kecamatan Palang akan penuh pada tahun 2026 dan Kecamatan Jenu akan penuh pada tahun 2028. Sehingga perlu adanya penambahan lokasi tempat pemakaman umum di Perkotaan Tuban khususnya di Kecamatan Tuban baik lokasi baru maupun peluasan areal tempat makam yang sudah ada. Hasil ini dikonfirmasi dengan kondisi eksisting survey primer Lahan Pemakaman Kecamatan Tuban yang paling mengalami tekanan daya tampungnya semakin sempi.

\section{DAFTAR PUSTAKA}

Anshori, M Sayfuddin. 2018. Penentuan Lokasi Makam Umum di Kota Kediri. Institut Teknologi Sepuluh Nopember

Badan Pusat Statistik Kabupaten Tuban. 2020. Kecamatan Merakurak Dalam Angka Tahun 2020. Tuban.

Badan Pusat Statistik Kabupaten Tuban. 2020. Kecamatan Palang Dalam Angka Tahun 2020. Tuban.

Badan Pusat Statistik Kabupaten Tuban. 2020. Kecamatan Semanding Dalam Angka Tahun 2020. Tuban.

Badan Pusat Statistik Kabupaten Tuban. 2020. Kecamatan Tuban Dalam Angka Tahun 2020. Tuban.

Badan Pusat Statistik Kabupaten Tuban. 2020. Perkotaan Tuhan Dalam Angka Tahun 2020. Tuban.

Pemerintah Kabupaten Tuban. 2017. Dokumen Penyusunan Perencanaan Ruang Terbuka Hijau Perkotaan. Tuban.

Ghea Amalia. 2016. Ketersediaan Lahan Tempat Pemakaman Umum (TPU) di Kota Surakarta. Jurnal Bumi Indonesia Vol. 5 no. 4

Diharto. 2011. Studi Penataan Kembali Tempat Pemakaman Umum (Studi Kasus TPU Kembang Arum Kota Semarang. Jurnal Teknik UNISFAT Vol. 6 No. 2.

Pemerintah Kabupaten Tuban. 2016. Peraturan Daerah Perkotaan Tuban Nomor 5 Tahun 2017 tentang Penyediaan, Penyerahan dan Pengelolaan Prasarana, Sarana dan Utilitas Perumahan dan Permukiman. Tuban.

Pemerintah Kabupaten Tuban. 2016. Peraturan Daerah Perkotaan Tuban Nomor 17 Tahun 2016 tentang Pengelolaan Taman Pemakaman. Tuban.

Pemerintah Kabupaten Tuban. Rencana Tata Ruang Wilayah Perkotaan Tuban tahun 2012-2032. Tuban. 